\section{Extinction of one snail but hope for others}

When the FFI Conservation Committee met recently it held a minute's silence to commemorate Partula turgida, a small snail from French Polynesia. The last individual of the species died in London Zoo at $17.30 \mathrm{~h}$ on 1 January. Although species are becoming extinct daily mostly undescribed vertebrates that are disappearing with their native habitat - such extinctions are seldom documented so precisely. The event was particularly poignant for FFI because the species was one rescued from the island of Raiatea in 1991 as part of a $100 \%$ Fund expedition. We have supported Partula spp. conservation since 1981 when it was brought to our attention that these snails were disappearing rapidly from the volcanic islands of the Pacific because of an introduced predatory snail Euglandina rosea. We hosted a Partula Snail Workshop in London in 1987, which produced a detailed captive-breeding programme to be implemented by 18 of the world's zoos and universities. Today there are 33 taxa in the breeding programme and it is perhaps inevitable that some are lost. Despite years of study there is still much to learn about the diet, disease and specific requirements of these small creatures and $P$. turgida, even in its death, contributed to the body of knowledge essential for making conservation progress.

The extinction of a snail would not normally be expected to arouse much interest among the general public and it was heartening that it captured the attention of the media in the UK, even a Church of England dignitary discussed it as an example of human folly in Thought for the Day on BBC's Radio 4.

Why are these snails considered so worthy of conservation attention? Within the range of Partula spp. each island had its own endemic snail fauna, with some species being restricted to single valleys. The product of extraordinary selective pressures, Partula snails have provided evolutionary geneticists with one of the most valuable examples of speciation - illuminating the processes by which new species originate. The snails are also part of traditional
Polynesian culture. Their shells, which have a lustrous sheen when alive or freshly dead, are used to make welcome necklaces, each valley having its own distinctive form. Traditional snail collection had little impact on the snail populations, but now, as Euglandina makes it inexorable destructive progress, the necklacemakers are losing their means of livelihood.

There is good news too, however. Captive populations of some of the snails are thriving and attempts are being made at reintroductions. In 1994 an international team built an enclosure on the island of Moorea, removed all individuals and eggs of Euglandina rosea and released captive-bred individuals of three species - $P$. suturalis from London Zoo, $P$. taeniata from Jersey Wildlife Preservation Trust and $P$. tohiveana from the University of Nottingham, UK. Sadly, on an FFI-assisted return trip to monitor the released snails in 1995, it was discovered that the enclosures had not been satisfactorily maintained. Euglandina had been able to penetrate the defences and almost all the Partula were dead. However, the presence of shells of young individuals and adults indicated that the introduction itself had been successful and that unconscious selection for survival and reproduction in captivity had not lowered the capacity for life in the wild. The enclosure was repaired and new arrangements were made for its maintenance.

Among the responses to our reader survey in 1993 was the comment that Oryx, and indeed FFI, appeared to concentrate on the large popular groups of animals, neglecting the most diverse faunal groups - arthropods and molluscs. It surprised me at the time because FFI appeared, more than any other international wildlife conservation organization, to try to redress the imbalance in funding that different taxonomic groups received. Our commitment to Partula conservation may be only a drop in the ocean. More important is the fact the Partula spp. have a dedicated band of conservationists working co-operatively world-wide to prevent their extinction Other invertebrate taxa certainly need this kind of dedicated attention to stem the enormous losses already occurring.

Jacqui Morris, Editor 